\title{
INTRODUCCIÓN: LA CARTA CULINARIA
}

\author{
ISHITA BANERJEE \\ El Colegio de México
}

Jeno basonar sera basa rasanae (sepa que el mejor nido del deseo se encuentra en la lengua). Así escribió en una de sus creaciones el poeta bengalí Rabindranath Tagore, premio Nobel de literatura. En este poema, llamado "Nimantran" ("Invitación”, publicado en Bithika, 1935), el poeta había evocado, de manera seductora, los placeres innatos del amor y el cuidado, articulados en el delicado acto de servir la comida, un acto que debía hacer la espera del amante un momento más seductor y completo gracias a la simultánea satisfacción de la mente y del cuerpo. Algunos años después, M. F. K. Fisher, la célebre escritora culinaria, subrayó los intrincados enredos de la necesidad humana de comida, seguridad y amor en el prefacio a su ahora clásico libro The Gastronomical Me. ${ }^{1}$ Están tan entremezclados, escribió ella, que es imposible pensar en uno sin pensar en los otros.

Este número especial toma su inspiración de estas declaraciones, similares y evocativas, hechas en distintas partes del mundo por un hombre y una mujer de culturas diferentes; intenta rastrear la interacción de creatividad, competencia, deseo y nostalgia en las distintas formas en las que la gente se relaciona con la comida y la cocina en diversas sociedades de Asia y África; examina el "papel dinámico" que juega la comida en la manera en que "las personas piensan sobre sí mismas y sobre otros" $\mathrm{y}$ la manera en que construyen lazos y fronteras. En otras palabras, los investigadores recurren en este volumen a los grandes avances que se han hecho en "estudios sobre

\footnotetext{
${ }^{1}$ M. F. K. Fisher, The Gastronomical Me, Farrar, Saraus y Giroux, 1943.

${ }^{2}$ Emiko Ohnuki-Tierney, Rice as Self: Japanese Identities through Time, Princeton, Princeton University Press, 1993, p. 3.
} 
los alimentos" en la última década y media, y los utilizan de forma imaginativa para proponer nuevos modos de entender la comida como medio de comunicación. Los artículos se enfocan en la interacción entre el acto de cocinar y la cocina, el proceso de ser persona y la nacionalidad, y la emoción y la subjetividad. Tomado en conjunto, este número se propone ofrecer una degustación - organizada en términos temáticos más que literales- que es al mismo tiempo tentadora y satisfactoria para los conocedores.

\section{Aperitivos}

Estamos conscientes de que la disciplina de la antropología mostró interés en la comida desde sus inicios. Algunos de los primeros practicantes de la disciplina, tales como Raymond Firth (1934), Bronislaw Manilowski (1935) y Cora Dubois (1941), habían señalado la centralidad de la comida en las culturas. Algunas décadas después, la antropología cultural tomó la batuta al destacar la importancia de la comida y las prácticas alrededor de la comida para las sociedades humanas y, por extensión, para las ciencias sociales. Los escritos clásicos de Claude LeviStrauss, ${ }^{3}$ Margaret Mead, ${ }^{4}$ Mary Douglas, ${ }^{5}$ Sidney Mintz, ${ }^{6}$ Pierre Bourdieu ${ }^{7}$ y Roland Barthes ${ }^{8}$ (por mencionar algunos), no sólo ofrecieron valiosos detalles etnográficos sobre los alimentos

${ }^{3}$ Claude Lévi-Strauss, "The Culinary Triangle", The Partisan Review, vol. 33, núm. 4, otoño de 1966, pp. 586-596; Claude Lévi-Strauss, The Raw and the Cooked: Introduction to a Science of Mythology, Londres, Jonathan Cape, 1970; Claude Lévi-Strauss, The Origin of Table Manners, Londres, Jonathan Cape, 1978.

${ }^{4}$ Margaret Mead, "Why do we Overeat?", Redbook Magazine, vol. 136, núm. 3, 1971 , pp. $28,30,33$.

${ }^{5}$ Mary Douglas, "Deciphering a Meal”, Daedalus (número especial: Myth, Symbol, and Culture), 1972, pp. 61-81.

${ }^{6}$ Sydney Mintz, "Time, Sugar and Sweetness", Marxist Perspectives, vol. 2, núm. 4, 1979, pp. 56-73.

7 Pierre Bourdieu, Distinction: A Social Critique of the Judgement of Taste, Londres, Routledge, 1984.

${ }^{8}$ Roland Barthes, "Toward a Psychosociology of Contemporary Food Consumption”, tr. Elborg Forster y Patricia M. Ranum, en Robert Foster y Orest Ranum (eds.), Food and Drink in History: Selections from the Annales, Economies, Societies, Civilizations Vol. 5 (original en francés, 1961, reimp. en inglés), Baltimore, Johns Hopkins University Press, 1979, pp. 166-173. 
y señalaron a la comida y la cocina como elementos cruciales de la cultura y del ser persona, también reflexionaron sobre la capacidad de la comida y la cocina para servir como códigos que transmiten significados sociales importantes. Algunos estudios antropológicos acerca de sociedades particulares complementaron estos escritos clásicos. Estos estudios antropológicos analizaban el papel del simbolismo religioso en las transacciones de comida y en los tabús culinarios. ${ }^{9}$ Otros trabajos de materialismo cultural - como el de Marvin Harris- rechazaron la semiótica para insistir en factores económicos y ecológicos como el motor detrás de la selección de elementos gustativos por pueblos particulares. ${ }^{10}$ Ciertos trabajos sobre nutrición, salud, agricultura y economía ofrecían interpretaciones del valor de la comida como sustento, mientras que importantes estudios examinaron la evolución de la comida en sociedades particulares desde perspectivas históricas y antropológicas. ${ }^{11}$ Además, algunos análisis profundos sobre las transformaciones de patrones culinarios ocasionadas por la industrialización ofrecieron perspectivas comparativas acerca de la comida en distintas sociedades $;^{12}$ otras lecturas innovadoras de libros de cocina puntualizaron las cambiantes configuraciones de la "cocina nacional”, ${ }^{13}$ y algunas lecturas histórico-antropológicas novedosas contribuyeron a explicar cómo un elemento particular de la comida aportaba a las cambiantes demarcaciones del sí mismo frente al otro en una cultura específica. ${ }^{14}$

El lento pero constante crecimiento en los "estudios de los alimentos" tuvo un estímulo importante a partir de la entrada

${ }_{9}^{9}$ Mckimm Marriott, "Caste Ranking and Food Transaction: A Matrix Analysis", en M. Singer y B. S. Cohn (eds.), Structure and Change in Indian Society, Chicago, Aldine, pp. 133-171; R. S. Khare, Culture and Reality: Essays on the Hindu System on Managing Foods, Shimla, Indian Institute of Advanced Study, 1976.

${ }^{10}$ Marvin Harris, Cowes, Pigs, Wars and Witches. The Riddles of Culture, Londres, Hutchinson and Co., 1975.

${ }^{11}$ K. C. Chang (ed.), Food in Chinese Culture: Historical and Anthropological Perspectives, New Haven, Yale University Press, 1977.

${ }^{12}$ Jack Goody, "Industrial Food: Towards the Development of a World Cuisine”, en Jack Goody, Cooking, Cuisine and Class: A Study in Comparative Sociology, Cambridge, Cambridge University Press, 1982, pp. 154-174.

${ }^{13}$ Arjun Appadurai, "How to Make a National Cuisine: Cookbooks in Contemporary India”, Comparative Studies in Society and History, vol. 30, núm. 1, enero de 1988, pp. 3-24.

${ }^{14}$ Ohnuki-Tierney, Rice as Self: Japanese Identities through Time, op. cit. 
del siglo XxI gracias a la participación de académicos de diversas disciplinas y la publicación de un vasto cuerpo de estudios interdisciplinarios, en especial de revistas. ${ }^{15}$ Poco a poco, geógrafos, filósofos, psicólogos, literatos, feministas y estudiosos del cine han roto el monopolio que antropólogos, historiadores, sociólogos y economistas tenían sobre la comida y la cocina, y han establecido los "estudios de los alimentos" como un campo de investigación válido y valioso. En la introducción a su influyente libro Food and Culture, ${ }^{16}$ Carole Counihan y Penny van Esterik alegan varias razones para esta explosión de estudios sobre la comida; el más importante es el papel jugado por feministas y académicas de estudios de la mujer al insistir en la necesidad de estudiar "un campo del comportamiento humano tan cercanamente asociado con las mujeres a través del tiempo y de las culturas". ${ }^{17}$ Esta insistencia, junto con la politización de la comida y el crecimiento de movimientos sociales asociados a la comida, hizo de los alimentos un tema legítimo de investigación académica. Una vez que ganó legitimidad, la "novedad, riqueza y alcance" de la comida abrió innumerables caminos que los académicos pueden seguir. ${ }^{18}$ Los trabajos sobre los alimentos tratan temas que van desde la comida y la identidad, hasta la hambruna, el género y las relaciones sociales. La historia de la comida, desde el banquete del renacimiento ${ }^{19}$ hasta su evolución en distintos países, es complementada por historias de alimentos específicos como el chocolate, ${ }^{20}$ la sa ${ }^{21} \mathrm{y}$ las especias. ${ }^{22} \mathrm{El}$ número de revistas dedicadas a la comida crece cada día; los textos literarios provocadores que aluden a recetas

\footnotetext{
${ }^{15}$ Appetite, Culture, and Agriculture; Food and Culture; Food and Foodways; Global Foodhistory, son algunos ejemplos.

${ }^{16}$ Carole Counihan y Penny van Esterik (eds.), Food and Culture: A Reader, Nueva York-Londres, Routledge, 2013.

${ }^{17}$ Carole Counihan y Penny van Esterik, "Why food? Why culture? Why now? Introduction to the third edition", en Food and Culture: A Reader, op. cit., p. 2.

${ }^{18}$ Idem.

${ }^{19}$ Ken Albala, The Banquet: Dining in the Great Courts of Late Renaissance Europe, Champagne-Urbana, University of Illinois Press, 2007.

${ }^{20}$ Sophie D. Coe y Michael D. Coe, The True History of Chocolate, Londres, Thames and Hudson, 2000.

${ }^{21}$ Mark Kurlansky, Salt: A World History, Nueva York, Penguin, 2003. 2004

${ }^{22}$ Jack Turner, Spice: The History of a Temptation, Nueva York, Vintage Books,
} 
de cocina para los corazones rotos van ganando importancia $;^{23}$ las películas que se enfocan en comida, sexualidad y relaciones sociales se están volviendo numerosas, y las competencias de cocina y los programas televisivos están alcanzando proporciones incontrolables. En resumen, una multitud de razones ha hecho que la comida y los alimentos se posicionen en el centro de atención y que investigadores de diferentes tonalidades y colores tengan un interés serio en la comida y la cocina como un modo que comunica mucho acerca de la cultura y el consumo, los humores y las emociones, el gusto y la identidad, el hambre y la carencia, y la jerarquía y la discriminación.

En este contexto, es más que apropiado que una revista que por décadas ha publicado artículos sobre sociedad y política, economía política y cultura de Asia y África, tome este importante paso de dedicar un número especial a la comida y la cocina. Este número especial se propone contribuir al siempre creciente campo de los estudios de los alimentos y explorar la comida y la emoción con la que se desarrolla en las relaciones sociales cotidianas, teniendo en cuenta las disputas y las contribuciones a la "filosofía culinaria" resueltas a través de la emoción y el afecto. ${ }^{24}$

Aunque las cuestiones sobre comida y desigualdad-discriminación no son tratadas directamente, sí son tomadas en cuenta en los ensayos que tocan temas como la alta cocina y la comida cotidiana, el papel de la mujer como procuradora de comida, las etiquetas en la mesa, las conceptualizaciones de lo femenino y lo masculino, la comida indígena y extranjera, y las asociaciones de la comida con hombres o mujeres. Los ensayos se ocupan de periodos, sociedades y regiones diversos; el tema común que los une es la consideración de cómo cocina y alimentos permiten a las personas articular no sólo lo que ellos son sino también lo que quieren ser; la interacción del amor y el conflicto, las luchas de poder y la nostalgia que son parte del proceso de convertir a la gente en personas y a grupos y comunidades en "culturas", son otros de los temas comunes a estos artículos.

${ }^{23}$ Laura Esquivel, Como agua para chocolate (1989), es uno de los primeros y más importantes ejemplos.

${ }^{24}$ Rachel Laudan, Cuisine and Empire. Cooking in World History, Berkeley-Los Ángeles, University of California Press, 2013. 


\section{Guisado}

El volumen comienza con un ensayo que permite un nuevo ángulo de visión sobre la larga lucha entre Israel y Palestina, uno que gira alrededor del hummus, platillo ubicuo y popular. Este puré de garbanzos molidos, sazonados con tabini y jugo de limón, que es extremadamente popular entre árabes y judíos, se volvió el centro de un acalorado debate entre Israel y Líbano sobre asuntos de derechos culturales de autor y herencia nacional, lo que llevó a una serie de competencias que contribuyeron a la cosificación del bummus como el elemento culinario clave de ambas naciones. La proporción, más que el sabor, fue crucial en las "guerras del bummus", cuando Líbano (Palestina) e Israel compitieron para ganar el récord mundial Guinness por el plato más grande de bummus. La etnografía crítica de Nir Avieli sobre uno de estos concursos en la villa palestino-israelí de Abu Gosh subraya cómo la competencia no era acerca de la comida y el sabor o las proporciones: era más bien sobre construcciones de identidad nacional, desordenada por la participación activa de grupos "minoritarios". Palestinos con ciudadanía israelí se involucraron apasionadamente en estos concursos a fin de compartir un sentido de pertenencia, y ofrecieron de ese modo nuevas maneras de construir "identidad" a través de la gastronomía.

A esto sigue un retorno en el tiempo, al final del siglo XIX y principios del xx en India, donde el discurso cultural del nacionalismo tomaba forma contra el dominio colonial británico. En el delineamiento de fronteras basadas en la "diferencia cultural” con Gran Bretaña, la nueva mujer, educada conforme lineamientos que eran propios de India, jugó un papel vital como la señora del nuevo modelo de familia. El segundo ensayo analiza las implicaciones del interés que se puso en la salud dentro de la configuración de una familia nueva y "moderna" como la base de una nación sana, y la importancia de la señora de la casa como la guardiana de la salud y la higiene familiares. A través de una cuidadosa lectura de viejos libros de cocina escritos en bengalí por mujeres (y hombres), columnas sobre comida en periódicos dirigidos por mujeres, y manuales domésticos escritos por hombres, Ishita Banerjee argumenta que las temáticas de salud y nutrición permitieron a hombres 
y mujeres construir un nuevo discurso sobre la familia, donde marido y mujer continuamente colaboraban para establecer su autoridad frente a los hombres y mujeres mayores (de la generación anterior) dentro de una familia extendida, e intentaban reemplazar la familia extendida con una familia nuclear. Las mujeres educadas, por su parte, se apropiaron creativamente del papel de la verdadera señora de esta familia y compitieron con sus rivales, tanto hombres como mujeres. Esta imaginativa exploración de batallas territoriales entrecruzadas posibilita a la autora extender el llamado de Mrinalini Sinha a expandir una concepción del género pensada sólo como lo que determina necesariamente las relaciones entre hombres y mujeres.

En el tercer ensayo, Cecilia Leong-Salobir traza la historia de encuentros coloniales en Malasia y Singapur de finales del siglo XIX y mediados del XX a través de una exploración de las prácticas coloniales alrededor de la comida. Ella echa un vistazo imaginativo al "colonizador" y el "colonizado" al analizar la relación entre la mem, la señora (o ama) británica blanca, y el cookie, el sirviente cocinero. Una lectura cuidadosa de libros de cocina coloniales y diarios, diarios de viaje y publicaciones de historiadores coloniales sobre comida, hacen a Leong-Salobir sostener que la cocina colonial fue el resultado de la inversión conjunta de energía y pasión de la mem y del cookie. Ciertamente, el papel del cookie fue vital en la creación de platillos únicos como el curry, la sopa al curry, el kitchiri, el pollo chop, el pish pash y el inimitable almuerzo llamado tiffin.

El cuarto y el quinto ensayos examinan, respectivamente, las connotaciones cruciales y la marcada presencia de la comida local en China contemporánea, y el significado sociocultural y religioso de la comida y las reglas de etiqueta en la mesa en la capital senegalesa de Dakar. Con la comida bezha - la comida local del suroeste de Hubei en China central- como su foco, $\mathrm{Xu} \mathrm{Wu}$ desmonta los muchos significados que ésta tiene en los discursos populares y los medios de comunicación. La comida hezha ha sido asociada con diversos significados en distintos periodos históricos: comida cotidiana y ordinaria, comida de granjeros, comida para pobres, comida de montaña, comida de hambruna, comida étnica, comida deliciosa y saludable, exquisitez servida a los extranjeros, comida de la ecología original, entre 
otras. Esta diversidad de significados ha hecho a la comida hezha flexible a variadas adaptaciones simbólicas y culinarias, incluida su estandarización en cadenas populares de restaurantes. Al subrayar las constantes transformaciones en los significados nacional e internacional de la comida, Xu Wu demuestra cómo dan lugar a la existencia simultánea de distintas y contradictorias connotaciones, en entendimientos separados acerca de la comida y la identidad.

María Guadalupe Aguilar hace hincapié en la importancia simbólica de la teranga - 'hospitalidad', en lenguaje wolof, que define a la cultura senegalesa- en sus explicaciones sobre la trascendencia de la comida y la cocina en las vidas cotidianas de la gente en Dakar. Además, la autora destaca el peso de las mujeres en actividades conectadas a la adquisición de comida y su preparación. El muy ordinario pero esencial viaje al mercado, por ejemplo, encarna una serie de papeles sociales y actividades culturales que abarcan a la mujer que va a comprar y a la vendedora que intenta ganarse la vida ofreciendo productos esenciales, como pescado, fruta, legumbres. Aguilar nos lleva por un recorrido desde el mercado hasta los hogares de familias extendidas para poner de relieve los diferentes significados de los papeles jugados por mujeres y hombres en la cocina cotidiana y en la cocina ritual, y analiza sus ramificaciones en la división del trabajo constituido por el género. Tales entendimientos, acordes con el género, también se llevan a cabo en las restricciones y la etiqueta que debe tenerse en la mesa, con la familia y durante los festivales rituales. Asimismo, tales normas fortalecen y desordenan las identidades de género en una sociedad en proceso de transición.

\section{Postre}

Dos ensayos, sobre Japón y Mozambique respectivamente, constituyen nuestro menú de postres. John D. Holtzman examina el "dulzor" como una metáfora de la interacción entre género e identidad en Japón. Traza la historia de los dulces, un aspecto ubicuo - pero poco discutido- de la cultura culinaria del Japón contemporáneo e histórico, para subrayar su trascendencia como 
un transmisor de significado. El azúcar y los dulces hechos de azúcar entraron a Japón, en el siglo XVI, gracias a los comerciantes portugueses y fueron rápidamente domesticados en una gran variedad de formas. Los dulces japoneses "tradicionales” y los recién (relativamente) adoptados de naciones occidentales, dice Holtzman, tienen distintas connotaciones socioculturales, así como una gran gama de usos sociales en el Japón contemporáneo. Si algunos señalan identidades locales, otros enuncian papeles de género, y definen estados de ánimo e identidades de personas. Los dulces, ampliamente asociados a las mujeres, también son centrales en el proceso de intercambio de regalos, un aspecto decisivo de la vida japonesa. En suma, afirma Holtzman, los dulces sirven como una llave para acceder a la cultura culinaria japonesa y al conocimiento de la vida japonesa en general.

El último ensayo ofrece un sabor agridulce. En él, Arianna Huhn se ocupa de cuestiones de antropofagia y tabús alimentarios en la cuidadosa construcción y demarcación de la persona y las comunidades en Mozambique. Los intercambios de comida y la comensalidad, argumenta la autora, son muy importantes para la pertenencia a la comunidad y para la existencia metafísica en una sociedad que valora profundamente el comportamiento "prosocial”. Esto significa que los tabús alimentarios constituyen una parte integral de la reproducción social. Huhn se enfoca en los tabús alimentarios en una ciudad africana para destacar la importancia de separar a las personas sociales de sus otros antisociales, despiadados e "inhumanos": los hechiceros. Los hechiceros intentan destruir la vida en lugar de mantenerla y mejorarla, y esto supone una predilección no sólo por crear miseria humana, sino también por consumir carne humana. Evitar carnes que se asemejen a la carne humana en forma física, emocional o espiritual es de suma importancia para los no hechiceros. Eso les ayuda a construir y afirmar sus identidades como sujetos "humanos".

\section{Sobremesa}

Para continuar la charla en la mesa después de un menú que esperamos haya satisfecho y abierto el apetito de nuestros lec- 
tores, ofrecemos una variedad de discusiones sobre comida en las secciones finales. Satomi Miura trae a colación la elaboración de un nuevo estilo de poesía en el periodo Edo del Japón premoderno. Este nuevo género, kigo, reflejaba la dinámica multilateral del periodo al mostrar las transformaciones en los patrones alimentarios correspondientes a la diversificación de productos agrícolas y marítimos en la comida, y al asociar elementos específicos de la comida con estaciones particulares, una combinación que evocaba una mezcla armoniosa de los viejos estilos y los nuevos sentimientos y ánimos que fueron transmitidos exitosamente. En otro pequeño ensayo, Soledad Jiménez nos permite observar instantáneas de la vida de una minoría poco estudiada en Kazajistán (anteriormente, la Unión Soviética), los dunganos, musulmanes que migraron desde China a finales del siglo XIX y que han ganado notoriedad por ser considerados "fósiles vivientes" debido a su resistencia al cambio. Jiménez se ocupa del asunto de la comida y la identidad como parte del "folclor", para reflexionar acerca de la resistencia a través de los alimentos como un componente de la diferencia cultural, y revelar los múltiples registros en los que el "folclor" funciona, todo a fin de argumentar que el "folclor" en el contexto de Asia central muestra "hegemonías en interacción" en las cuales la comida y los modos de acercarse a ella y consumirla juegan un papel decisivo en la construcción de narrativas transnacionales, nostálgicas, resistentes y culturalmente diferentes. Finalmente, Camila Pastor nos invita a conocer su propia pasión por la comida y los estudios sobre los alimentos, al mostrarnos un recuento completo y crítico de nuevos trabajos sobre comida, particularmente en relación con Medio Oriente, y los diferentes caminos tomados por los estudios de los alimentos en el proceso de su evolución. En suma, este número aspira a servir un platillo que guste al paladar de los entusiastas sagaces. 